Research Article

\title{
Oriental Leafhopper (Hemiptera: Cicadellidae: Parallygus) First Report from North West Pakistan with Redescription of Parallygus rameshi Viraktamath and Webb
}

\author{
Hassan Naveed ${ }^{1 *}$, Kamran Sohail ${ }^{2}$, Gul Zamin Khan ${ }^{3}$ and Yalin Zhang $^{2}$ \\ ${ }^{1}$ College of Life Science, Leshan Normal University, Leshan, Sichuan 614004, China; ${ }^{2}$ Key Laboratory of Plant Protection \\ Resources and Pest Management of Ministry of Education, Entomological Museum, Northwest A\& F University, Yangling, \\ Shaanxi Province 712100, China; ${ }^{3}$ Nuclear Institute for Food and Agriculture (NIFA), G. T. Road Tarnab, Peshawar, Khyber \\ Pakhtunkhwa, Pakistan.
}

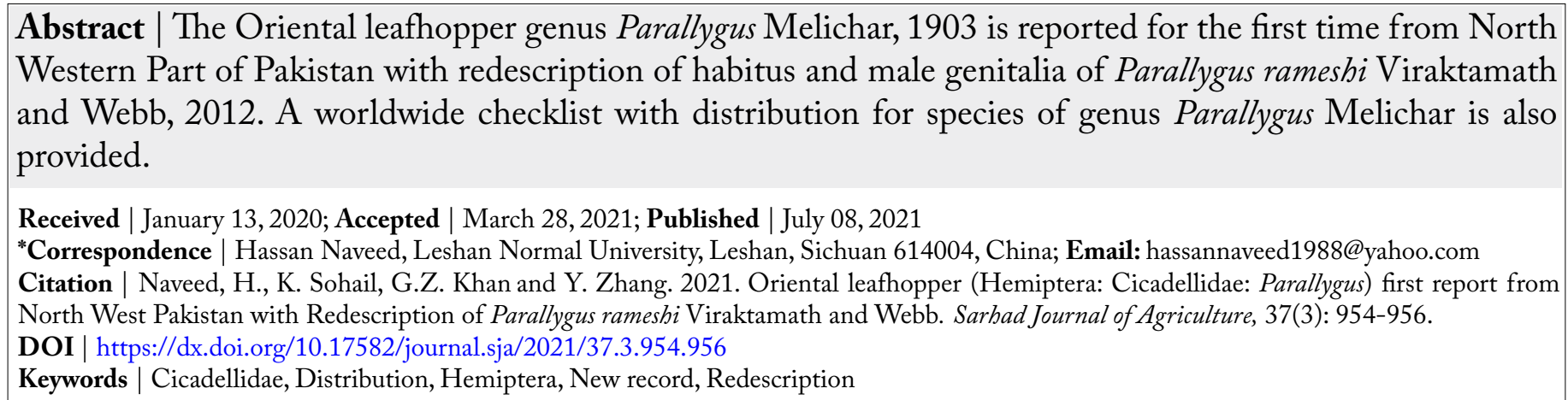

\section{Introduction}

$\mathrm{O}$ riental leafhopper from genus Parallygus was established by Melichar(1903) with P. divaricatus Melichar as its type species from Sri Lanka. The genus Parallygus was first placed in tribe Athysanini due to its paired aedeagal shafts (Metcalf, 1967; Oman et al., 1990; Dai et al., 2012) but transferred to Scaphoideini (Zahniser and Dietrich, 2013). This genus was comprehensively studied for the first time by Dai et al. (2012) where they revised it with description of three species from China and India. Till date, only 5 species under this genus are reported form Oriental region. Genus Parallygus resembles other closely related genera i.e., genus Platyretus Melichar (1903), Scaphoidophyes Kirkaldy (1906) and Capoideus Theron (1974) in some external features and appearance but can be separated from all genera on the basis of genital characters having infolded subgenital plates with slightly degenerated style apophysis lodged into them, connective $\mathrm{U}$ or $\mathrm{V}$-shaped devoid of stem or with divided arms articulating with the aedeagus independently, aedeagus with paired shafts and two gonopores, with or without pair of ventral posteriorly directed blade-like processes, females with simple plate-like seventh sternite as compared to others (Dai et al. 2012).

Examined specimens were deposited in the College of Life Science, Leshan Normal University, Leshan, Sichuan, China (LSNU).

\section{Materials and Methods}

Morphological terminology follows Dietrich (2005). The specimens were observed and dissected under a stereo microscope (Zoom, 2000, Leica) for studying genital characters like pygofer, aedeagus, connective, 
style and sub genital plates. Photos and measurements of adult leafhopper were taken by a ZEISS Stereo Discovery V20 stereomicroscope equipped with a ZEISS Axiocam ICc5 camera. Layers of photos were taken at different focal points with Q Imaging CCD camera and combined to form a single image from layer of images through Auto-Montage software. Photographs were processed for stabilization through Adobe Photoshop CS.

\section{Genus Parallygus Melichar, 1903}

Parallygus Melichar,1903:179.Type species: Parallygus divaricatus Melichar, by original designation.

Note: For genus description see Dai et al., 2012: 4244.

Checklist of genus Parallygus melichar worldwide distribution.

Parallygus burmindicus Viraktamath and India

Webb, 2012

Parallygus divaricatus Melichar, 1903 Sri Lanka

Parallygus guttatus (Matsumura, 1914) China, India

Parallygus jiuhuaensis Dai and Zhang, 2012 China

Parallygus rameshi Viraktamath and Webb, India, Pakistan

2012

(Swat) new record

Parallygus rameshi Viraktamath and Webb, 2012.

Measurements. body length (mm): $₫ \quad 6.1-6.4 ;$; 6.4 .

crown width including eyes, $1.46 \mathrm{~mm}$; crown length, $0.37 \mathrm{~mm}$; pronotum width, $1.62 \mathrm{~mm}$; pronotum length, $0.72 \mathrm{~mm}$; scutellum width, $0.62 \mathrm{~mm}$; scutellum length, $0.61 \mathrm{~mm}$.

\section{Description of male}

Color: Ochraceous in general coloration (Figure 1A); crown, pronotum, scutellum and forewings with dark brown markings (Figure 1A); face whitish yellow (Figure 1B); frontoclypeus with dorsal dark brown to black spot, lateral margin with oblique brown spots (Figure 1B); anteclypeus with pair of basal brownish spots (Figure 1B).

Head: narrower than pronotum (Figure 1A); face (including eyes) as wide as long, antennal pits shallow, rather transgressing margins of frontoclypeus, transclypeal sulcus complete, clypellus with lateral margins concave, slightly widened apically (Figure 1B); eyes large; ocelli prominent, very close to eyes; labium usually not exceeding prosternum; pronotum with lateral margins carinate, anterior margin rounded, posterior margin slightly concave; scutellum as long as pronotum or slightly shorter; forewings with claval veins usually separate; three subapical cells and four apical cells.
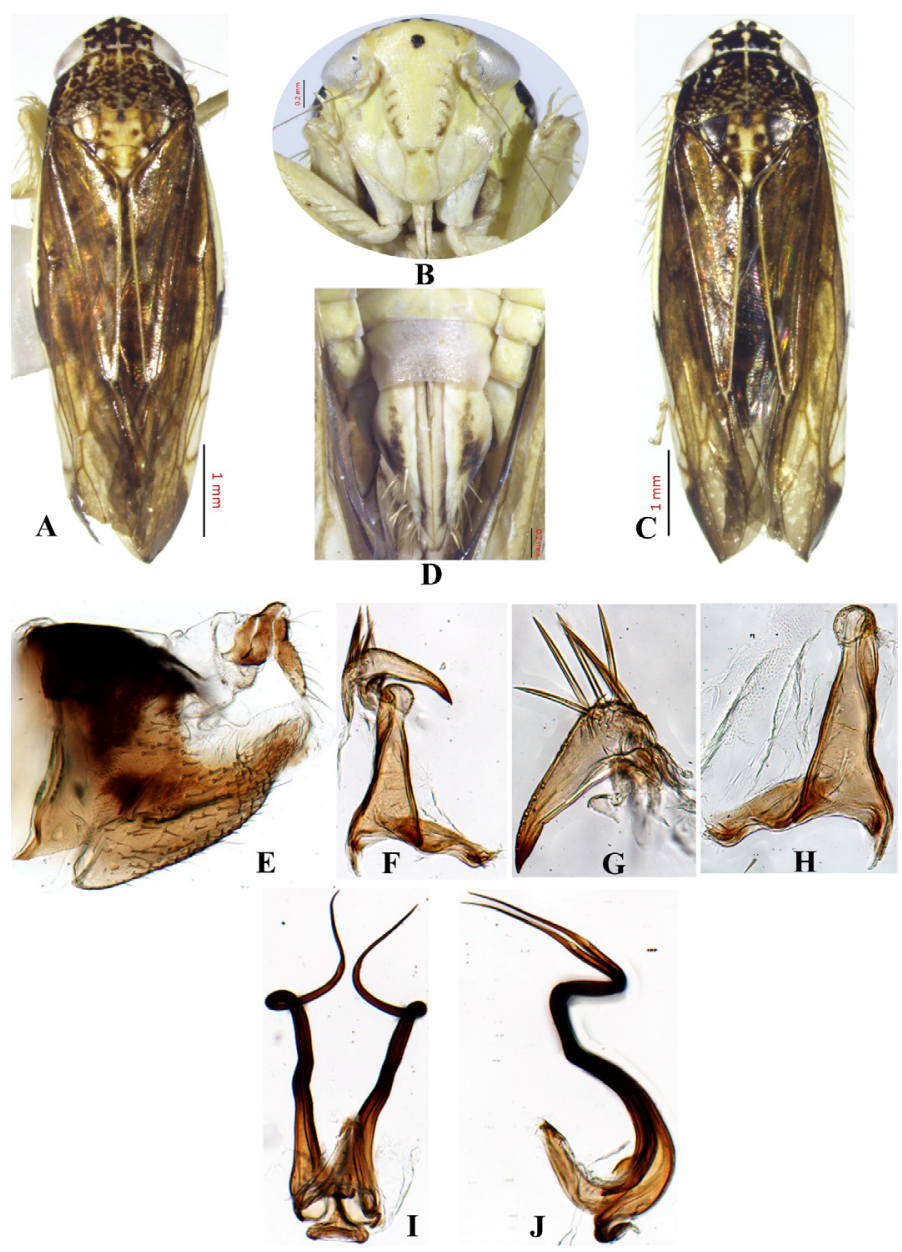

Figure 1: Parallygus rameshi Viraktamath and Webb. (A) Habitus, dorsal view Ō; (B) Face; (C) Habitus, dorsal view $O$; (D) Female seventh sternite, ventral view; (E) Pygofer lobe, lateral view ô; (F) Subgenital plate and style, dorsal view ô; (G) Subgenital plate, dorsal view ô;; (H) Style, dorsal view गे; (I) Aedeagus, dorsal view and (J) Aedeagus, lateral view.

Pygofer lobe slightly longer than high, posteriorly rounded, with posterodorsal rounded membranous lobe; posterior half with macrosetae (Figure 1E); subgenital plates slightly semi-circular, apically rounded with few macrosetae, with anterior pointed extension (Figure 1F-G). Connective without stem, arms divided, articulated independently with base of shaft (Figure 1I). Aedeagus dorsal apodeme well developed, with two shafts, each shaft gradually narrowed towards apex, strongly sinuately curved with attenuated apex extending beyond gonopore (Figure 1I-J). Gonopore subapical (Figure 1J).

Material examined: $(\mathbf{n}=3,2 \hat{\jmath}, 1$ ) $)$ Pakistan: Khyber Pakhtunkhwa: Swat, $35.2227^{\circ} \mathrm{N}, 72.4258^{\circ} \mathrm{E}, 975 \mathrm{~m}$, 
14-viii-2019, coll. Hassan Naveed.

Distribution: India, Pakistan (Swat) new record.

\section{Results and Discussion}

This species was only described from India and here first time reported from Swat, Khyber Pakhtunkhwa, Pakistan during recent collection trip in 2019. All specimens were collected by net sweeping from grasses. Here, redescription of the habitus and male genitalia along with their photographs in detail is provided for easy identification of Parallygus rameshi. Collection of this species from Pakistan suggests that this genus needs more efforts to be explored from this area.

\section{Acknowledgments}

This study is supported by the key scientific research project of university-level discipline construction of Leshan Normal University (LZD029).

\section{Novelty Statement}

The leafhopper genus Parallygus is reported and described for the first time from Pakistan with colored photographs of habitus and male genitalia.

\section{Author's Contribution}

Hassan Naveed: Species description and manuscript writing.

Kamran Sohail: Technical guidelines.

Gul Zamin Khan and Yalin Zhang: Proofreading of the manuscript.

\section{Conflict of interest}

The authors have declared no conflict of interest.

\section{References}

Dai, W., C.A. Viraktamath, M.D. Webb and Y.L. Zhang. 2012. Revision of the oriental leafhopper genus Parallygus Melichar (Hemiptera: $\mathrm{Ci}^{-}$ cadellidae: Deltocephalinae) with description of new species. Zootaxa, 3157: 41-53. https:// doi.org/10.11646/zootaxa.3157.1.4

Dietrich, C.H. 2005. Keys to the families of Cicadomorpha and subfamilies and tribes of
Cicadellidae (Hemiptera: Auchenorrhyncha). Florida Entomol., 88: 502-517. https://doi. org/10.1653/0015-4040(2005)88[502:KTTF $\mathrm{OC}] 2.0 . \mathrm{CO} ; 2$

Kirkaldy,G.W.1906.Leaf-hoppers and their natural enemies. (Pt. IX Leaf-hoppers. Hemiptera). Report of work of the Experiment Station of the Hawaiian Sugar Planters' Association. Div. Entomol. Bull., 1(9): 271-479.

Matsumura, S. 1914. Die Jassinen and einigeneue Acocephalinen Japans. J. Sapporo Agric. Coll., Sapporo, Japan. 5(7): 165-240.

Melichar, L. 1903. Fauna von Ceylon.iv+248. Verlag von Felix L. Dames, Berlin.

Metcalf, Z.P. 1967. A general Catalogue of the Homoptera. Fascicle Vi. Cicadelloidea. Part 10. Section I. Euscelidae. U.S. Dept. Agric. Agric. Res. Serv., pp. 1077.

Oman, P.W., W.J. Knight and M.W. Nielson. 1990. C.A.B. Int. Inst. Entomol., pp. 368.

Theron, J.G. 1974. The Naudé species of South African Cicadellidae (Hemiptera). III. Species assigned to the genus Chlorotettix Van Duzee, Thamnotettix Zetterstedt, Euscelis Brullé, Scaphoideus Uhler and Selenocephalus Germar. J. Entomol. Soc. S. Afr., 37(1): 147-166.

Zahniser, J.N. and C.H. Dietrich. 2013. A review of the tribes of Deltocephalinae (Hemiptera: Auchenorrhyncha: Cicadellidae). Eur.J.Taxon., 45: 1-211. https://doi.org/10.5852/ejt.2013.45

September 2021 | Volume 37 | Issue 3 | Page 956 